\title{
Optimization of ultrasound-assisted extraction of procyanidins from perilla seed hull and their antioxidant activities in vitro
}

\author{
Hui-Zhen LI $^{1}$, Yong-Lan TAN ${ }^{1}$, Zhi-Jun ZHANG ${ }^{1 \star}$, Yao-Yao XIA ${ }^{1}$, Xiao-Jun LI ${ }^{1}$, Li-Xia CUI ${ }^{1}$, Tie CHEN
}

\begin{abstract}
Ultrasound-assisted extraction (UAE) was used to extract procyanidins (PC) from the perilla seed hull. Four independent variables, namely, liquid-to-solid ratio, ethanol concentration, UAE time, and UAE temperature were investigated. Response surface methodology was performed on the basis of results of single-factor tests. The optimal conditions for PC extraction were as follows: a liquid-to-solid ratio of 15:1, an ethanol concentration of 62\%, a UAE time of $29 \mathrm{~min}$, and a UAE temperature of $53^{\circ} \mathrm{C}$. Under these conditions, the experimental yield of PC was $2.185 \mathrm{mg} / \mathrm{g}(\mathrm{n}=3)$, which is correlated with the predicted value of $2.2 \mathrm{mg} / \mathrm{g}$. The extracted and purified PC showed excellent antioxidant activity against 2,2-diphenyl-1-picrylhydrazyl, hydroxyl, and 2,2'-azino-bis (3-ethylbenzothiazoline-6-sulfonic acid) radicals in vitro.
\end{abstract}

Keywords: perilla seed hull; ultrasound-assisted extraction; procyanidins; antioxidant activities.

Practical Application: The study provides valuable information that ultrasound-assisted extraction is an efficient, environment-friendly, and green process for the preparation of extracts from perilla seed hull, and will help in the development of a naturally potential antioxidant for pharmaceutical and food industries.

\section{Introduction}

Perilla (Perilla frutescens), an aromatic vegetable, is widely used for cooking and medicinal purposes in several Asian countries such as China, Korea, Japan, and Thailand (Igarashi \& Miyazaki, 2013; Li et al., 2015). The seeds of P. frutescens have been shown to have antimicrobial and inhibitory activities against $\alpha$-glucosidase and aldose reductase (Ha et al., 2012; Liu et al., 2013). The oil from perilla seeds contains high levels of a-linolenic acid (ALA, C18:3) (Shin \& Kim, 1994; Seong \& Song, 2012), which range from $52.58 \%$ to $61.98 \%$ (Ciftci et al., 2012; Zhou et al., 2014). Studies have reported that high levels of ALA, a precursor of eicosapentaenoic acid and docosahexaenoic acid, confers perilla seed oil the potential to lower the risk for multiple chronic diseases (Asif, 2011; Li et al., 2014). The protein content of whole perilla seed has been reported to be in the range of 15.7-23.7\% (Sharma et al., 1989). The essential amino acids of perilla whole seed meal represent $39 \%$ of its total amino acids. Dehulling can not only improve perilla seed oil and protein production (Longvah \& Deosthale, 1998), but it also can help reduce the bitter taste, increase the transparency of the oil, and reduce the pigment content of the protein, making the protein color lighter. Along with the rapidly expanding global demand for perilla oil and protein manufacturing processes, the amount of waste perilla seed hull has increased. The final by-products that pose minimal or no environmental risks will be an important issue faced by perilla production industries. Studies have shown that procyanidins are present in many plant fruits, seeds, hulls, peels, flowers, leaves, and stems; thus, perilla seed hull may be a source of bioactive procyanidins that should not be overlooked. Therefore, intensive processing and utilization of waste resources for obtaining valuable products have high significance. These products may be useful to the pharmaceutical or food industries (Moure et al., 2001), turn waste into wealth, and increase its medicinal value and economic benefits.

Procyanidins, a widespread family of polyphenol polymers of flavan-3-ol, are plant secondary metabolites that can be found in a number of plant-based foods and beverages (Hammerstone et al., 2000; Berendsen et al., 2015). Procyanidins have various chemical and biological functions, including ultraviolet (UV) absorption, as well as antimicrobial, anti-inflammatory, anti-allergic, and antioxidant properties (Su et al., 2010; Yang et al., 2012; Aneta et al., 2013; Cruz et al., 2015). A study has established that higher dietary intakes of procyanidins are associated with lower risks of cancers (Santos-Buelga \& Scalbert, 2000). The health benefits of procyanidins indicate that they are potentially useful as food antioxidants and nutraceuticals. The significance of antioxidants in preventive medicine is well known. Increasing interest in the search for new, safe, non-toxic, effective natural antioxidants has emerged because of their significant benefits. Despite the many techniques for determining polyphenols, reports on the feasible and economic extraction of PC from perilla seed hull in relation to the antioxidant activities of the extract are limited. So far, there is a lack of literature about multivariate optimization strategies such as response surface methodology (RSM) for PCs, a tool first introduced by Box and Wilson (Box \& Wilson, 1951). RSM can be used to evaluate the effects of multiple factors and their interactions with one or more response variables via statistical analysis of a mathematical model 
(Xu et al., 2013; Azmir et al., 2014; Díaz-de-Cerio et al., 2017). It has been successfully used in the extraction of polyphenols from natural sources (Zeković et al., 2014; Chen et al., 2015). Therefore, the main objective of this study was to find an optimum ultrasound-assisted extraction (UAE) of PC from perilla seed hull using RSM. The in vitro antioxidant activities of the new derivatives in the 2,2-diphenyl-1-picrylhydrazyl (DPPH), hydroxyl, and 2,2'-azino-bis (3-ethylbenzothiazoline-6-sulfonic acid) (ABTS) assays were performed.

\section{Materials and methods}

\subsection{Plant materials}

P. frutescens seed hulls were obtained in December 2016 by Shanxi Jinqiao Cereals Industry Co., Ltd. (Taiyuan, Shanxi Province, China). The hulls were air-dried at ambient temperature $\left(\sim 25^{\circ} \mathrm{C}\right)$, milled, passed through a stainless-steel sieve to approximately $250 \mu \mathrm{m}$, and stored in closed desiccators at $4{ }^{\circ} \mathrm{C}$ until use.

\subsection{Chemicals}

2,2-Diphenyl-1-picrylhydrazyl (DPPH), 2,2'-azino-bis (3-ethylbenzothiazoline-6-sulphonic acid) (ABTS), Folin-Ciocalteu (FC) reagent, Gallic acid and vitamin $C$ were purchased from Sigma Chemical Co. (St. Louis, MO, USA). Analytical grade ethanol, hydrochloric acid and sodium carbonate were purchased from Tianjin Guangfu Chemical Reagent Co., Ltd. (Tianjin, China).

\subsection{Ultrasound-assisted extraction of procyanidins}

Extractions were carried out in a tunable ultrasonic bath (TH-400BQG, 50 kHz, $400 \mathrm{~W}$; Tianhua Ultrasonic Electronic Equipment Co., Jining, Shandong, China). A 2 g sample of the dried perilla seed hull powder was extracted with aqueous ethanol several times until the filtrate contained no PC as detected by $\mathrm{FeCl}_{3} / \mathrm{K}_{3} \mathrm{Fe}(\mathrm{CN})_{6}$. The filtrates were then combined and centrifuged for $10 \mathrm{~min}$ at $4000 \mathrm{~g}$, the supernatant was filtered through 0.45 nylon syringe filters, and the PC content was determined.

\subsection{Single factor experiments}

The effect of liquid-to-solid ratio on the PC content was determined at different ratios $(5: 1,10: 1,15: 1,20: 1$, and 25:1) of the extraction solvent, $70 \%$ ethanol solution, a UAE time of $30 \mathrm{~min}$, and an UAE temperature of $50{ }^{\circ} \mathrm{C}$. The effect of ethanol concentration $(50 \%, 60 \%, 70 \%, 80 \%$, and $90 \%)$ on the PC content was determined at a liquid-to-solid ratio of 15:1, a UAE time of $30 \mathrm{~min}$, and a UAE temperature of $50^{\circ} \mathrm{C}$. The effect of UAE time $(10,20,30,40$, and $50 \mathrm{~min})$ on the PC content was determined at a liquid-to-solid ratio of 15:1, an ethanol concentration of $60 \%$, and a UAE temperature of $50{ }^{\circ} \mathrm{C}$. Finally, the effect of UAE temperature $\left(30,40,50,60\right.$, and $\left.70{ }^{\circ} \mathrm{C}\right)$ on the PC content was determined at a liquid-to-solid ratio of 15:1, an ethanol concentration of $60 \%$, and a UAE time of $30 \mathrm{~min}$.

\subsection{RSM design and statistical analysis}

Based on the single-factor experiments, a Box-Behnken design (BBD) was used to determine the effects of four independent variables, i.e., liquid-to-solid ratio $\left(X_{1}\right)$, ethanol concentration
$\left(X_{2}\right)$, UAE time $\left(X_{3}\right)$, and UAE temperature $\left(X_{4}\right)$ on the PC content $(Y)$. The complete design consisted of 29 experimental points including five replications of the central points (all variables were coded as zero), with three levels $(-1,0$, and 1$)$ for each factor. A randomized experimental order was used to reduce the effect of unexplained variability on the observed response. The run order, variable conditions, and the experimental values are shown in Table 1. A second-order polynomial equation derived from RSM was used:

$$
\begin{aligned}
& Y=b_{0}+b_{1} X_{1}+b_{2} X_{2}+b_{3} X_{3}+b_{4} X_{4}+ \\
& b_{12} X_{1} X_{2}+b_{13} X_{1} X_{3}+b_{14} X_{1} X_{4}+b_{23} X_{2} X_{3}+ \\
& b_{24} X_{2} X_{4}+b_{34} X_{3} X_{4}+b_{11} X_{1}{ }^{2}+b_{22} X_{2}{ }^{2}+b_{33} X_{3}{ }^{2}+b_{44} X_{4}{ }^{2}
\end{aligned}
$$

where $Y$ is the response variable (PC content); $b_{0}, b_{1}, b_{2}, b_{3}, b_{4}$, $b_{11}, b_{22}, \ldots$ are the regression coefficients; and $X_{1}, X_{2}, X_{3}$, and $X_{4}$ are independent factors for the liquid-to-solid ratio, ethanol concentration, UAE time, and UAE temperature, respectively.

Data were analyzed using analysis of variance (ANOVA) to determine the lack of fit and the effects of linear, quadratic, and interaction variables on the PC content. Data analysis and RSM were performed with Design Expert software (Version 8; Stat-Ease, Inc., Minneapolis, MN, USA).

\subsection{Determination of procyanidins}

The procyanidin content was determined through the vanillin-sulfuric acid method (Liu et al., 2010) with slight modifications. Standard solutions containing 0, 0.025, 0.05, $0.075,0.1,0.125$, and $0.15 \mathrm{mg} / \mathrm{mL}$ PC were prepared. A $1 \mathrm{~mL}$ portion was transferred to different test tubes and then mixed with $3 \mathrm{~mL}$ of $30 \%$ sulfuric acid/methanol solution and $6 \mathrm{~mL}$ of $30 \mathrm{~g} / \mathrm{mL}$ vanillin/methanol solution, and then the mixture was kept at $30^{\circ} \mathrm{C}$ for $30 \mathrm{~min}$. The absorbance at $500 \mathrm{~nm}$ was checked using a UV-visible spectrophotometer (UV9600; Bobang Co., Zhengzhou, China), and then the standard PC absorbance curve was plotted. The sample was then processed in the same way. The PC content was expressed in milligrams per gram of dry weight of perilla seed hulls.

\subsection{Purification of the crude extract}

The extract was purified following a procedure in the literature (Zhang et al., 2011), with some modifications. A glass column $(3.0 \mathrm{~cm} \times 66.0 \mathrm{~cm})$ was filled with $25.0 \mathrm{~g}$ of XDA-8 resin. The sample with a PC content of $0.21 \pm 0.01 \mathrm{mg} / \mathrm{mL}$ was dissolved in distilled water and then loaded with a current pump at a speed of $4 \mathrm{BV} / \mathrm{h}$. The eluate was step-collected $(10 \mathrm{~mL} /$ tube $)$ and the PC content was determined. Loading was stopped at the adsorption permeation point (the point at which the PC content of the eluate was $1 / 10$ that of the loaded sample). The resin was washed with $60 \mathrm{~mL}$ of distilled water to remove sugars, aliphatic acids, and other impurities. Subsequently, the absorbed phenolic compounds and PC were eluted slowly with $13 \mathrm{BV}$ of $70 \%$ aqueous ethanol at a speed of $2 \mathrm{BV} / \mathrm{h}$. The eluate was collected, evaporated, and freeze-dried (Scientz-10N; Xinzhi Ltd., Ningbo, China) for further study of the antioxidant and anticancer activities. 
Table 1. Box-Behnken design and the response values for PC content using UAE.

\begin{tabular}{|c|c|c|c|c|c|}
\hline Run & $\begin{array}{c}\text { Liquid-solid ratio } \\
X_{1}(\mathrm{~mL}: \mathrm{g})\end{array}$ & $\begin{array}{c}\text { Ethanol concentration } \\
X_{2}(\%)\end{array}$ & $\begin{array}{l}\text { UAE time } \\
X_{3}(\min )\end{array}$ & $\begin{array}{c}\text { UAE temperature } \\
X_{4}\left({ }^{\circ} \mathrm{C}\right)\end{array}$ & $\begin{array}{l}\text { PC content } \\
(\mathrm{mg} / \mathrm{g})\end{array}$ \\
\hline 1 & $15: 1(0)$ & $60(0)$ & $20(-1)$ & $40(-1)$ & 1.769 \\
\hline 2 & $15: 1(0)$ & $50(-1)$ & $40(1)$ & $50(0)$ & 1.139 \\
\hline 3 & $15: 1(0)$ & $70(1)$ & $30(0)$ & $40(-1)$ & 1.498 \\
\hline 4 & $15: 1(0)$ & $60(0)$ & $30(0)$ & $50(0)$ & 2.051 \\
\hline 5 & $15: 1(0)$ & $50(-1)$ & $30(0)$ & $60(1)$ & 1.450 \\
\hline 6 & $10: 1(-1)$ & $50(-1)$ & $30(0)$ & $50(0)$ & 1.515 \\
\hline 7 & $20: 1(1)$ & $60(0)$ & $20(-1)$ & $50(0)$ & 1.815 \\
\hline 8 & $15: 1(0)$ & $60(0)$ & $30(0)$ & $50(0)$ & 2.168 \\
\hline 9 & $10: 1(-1)$ & $70(1)$ & $30(0)$ & $50(0)$ & 1.860 \\
\hline 10 & $15: 1(0)$ & $60(0)$ & $40(1)$ & $40(-1)$ & 1.367 \\
\hline 11 & $15: 1(0)$ & $60(0)$ & $30(0)$ & $50(0)$ & 2.167 \\
\hline 12 & $15: 1(0)$ & $70(1)$ & $40(1)$ & $50(0)$ & 1.650 \\
\hline 13 & $10: 1(-1)$ & $60(0)$ & $30(0)$ & $40(-1)$ & 1.696 \\
\hline 14 & $10: 1(-1)$ & $60(0)$ & $30(0)$ & $60(1)$ & 1.880 \\
\hline 15 & $15: 1(0)$ & $50(-1)$ & $30(0)$ & $40(-1)$ & 1.701 \\
\hline 16 & $20: 1(1)$ & $60(0)$ & $30(0)$ & $60(1)$ & 1.993 \\
\hline 17 & $15: 1(0)$ & $70(1)$ & $20(-1)$ & $50(0)$ & 1.802 \\
\hline 18 & $15: 1(0)$ & $60(0)$ & $20(-1)$ & $60(1)$ & 1.751 \\
\hline 19 & $20: 1(1)$ & $70(1)$ & $30(0)$ & $50(0)$ & 1.750 \\
\hline 20 & $10: 1(-1)$ & $60(0)$ & $20(-1)$ & $50(0)$ & 1.599 \\
\hline 21 & $20: 1(1)$ & $60(0)$ & $40(1)$ & $50(0)$ & 1.612 \\
\hline 22 & $15: 1(0)$ & $60(0)$ & $30(0)$ & $50(0)$ & 2.165 \\
\hline 23 & $15: 1(0)$ & $50(-1)$ & $20(-1)$ & $50(0)$ & 1.730 \\
\hline 24 & $20: 1(1)$ & $50(-1)$ & $30(0)$ & $50(0)$ & 1.688 \\
\hline 25 & $10: 1(-1)$ & $60(0)$ & $40(1)$ & $50(0)$ & 1.788 \\
\hline 26 & $20: 1(1)$ & $60(0)$ & $30(0)$ & $40(-1)$ & 1.699 \\
\hline 27 & $15: 1(0)$ & $60(0)$ & $30(0)$ & $50(0)$ & 2.172 \\
\hline 28 & $15: 1(0)$ & $60(0)$ & $40(1)$ & $60(1)$ & 1.798 \\
\hline 29 & $15: 1(0)$ & $70(1)$ & $30(0)$ & $60(1)$ & 1.890 \\
\hline
\end{tabular}

$\mathrm{UAE}=$ Ultrasound-assisted extraction; $\mathrm{PC}=$ procyanidins.

\subsection{DPPH radical scavenging activity}

DPPH radical scavenging activity was determined according to the method reported by Choi et al. (2000) with some modification. In brief, $0.3 \mathrm{~mL}$ of sample was mixed with $2.7 \mathrm{~mL}$ of $60 \mu \mathrm{M}$ DPPH radical solution in methanol. The mixture was then shaken vigorously and incubated for $30 \mathrm{~min}$ at room temperature in the dark. The absorbance at $518 \mathrm{~nm}$ was measured using a UV-visible spectrophotometer (UV9600; Bobang Co., China). Results were expressed as percentage inhibition of the DPPH radical. Percentage inhibition of the DPPH radical was calculated as follows (Equation 2:

DPPH scavenging activity $(\%)=\left[\begin{array}{l}\left(O D_{\text {control }}-O D_{\text {sample }}\right) / \\ O D_{\text {control }}\end{array}\right] \times 100(2)$

where $\mathrm{OD}_{\text {sample }}$ is the absorbance of the test sample (DPPH solution plus test sample); and $\mathrm{OD}_{\text {control }}$ is the absorbance of the control (DPPH solution without sample).

\subsection{Hydroxyl radical scavenging activity}

The hydroxyl radical scavenging ability was performed using the method described by Avellar et al. (2004) with some modifications. 1,10-Phenanthroline ( $1 \mathrm{~mL}, 0.75 \mathrm{mmol} / \mathrm{L})$ and
$\mathrm{Fe}_{2} \mathrm{SO}_{4}(0.5 \mathrm{~mL}, 0.75 \mathrm{mmol} / \mathrm{L})$ were dissolved in $1 \mathrm{~mL}$ of phosphate buffer ( $\mathrm{pH} 7.4)$ and mixed thoroughly. $\mathrm{H}_{2} \mathrm{O}_{2}(0.5 \mathrm{~mL}, 0.1 \mathrm{~mL} / \mathrm{L})$ and $1 \mathrm{~mL}$ of PC fractions at different concentrations $(0.6,0.8$, $1.0,1.2,1.4,1.6,1.8$, and $2.0 \mathrm{mg} / \mathrm{mL}$ ) were added. The mixture was incubated at $37^{\circ} \mathrm{C}$ for $60 \mathrm{~min}$, and then the absorbance was measured at $536 \mathrm{~nm}$. The hydroxyl radical $(\cdot \mathrm{OH})$ scavenging activity was determined using the following Equation 3:

OH scavenging activity $(\%)=\left[\begin{array}{c}\left(A_{s}-A_{b}\right) / \\ \left(A_{0}-A_{b}\right)\end{array}\right] \times 100$

where $A_{\mathrm{s}}$ is the absorbance of the sample; $A_{\mathrm{b}}$ is the absorbance of the control solution containing 1,10-Phenanthroline, $\mathrm{Fe}_{2} \mathrm{SO}_{4}$ and $\mathrm{H}_{2} \mathrm{O}_{2}$; and $A_{0}$ is the absorbance of the blank solution containing 1,10-Phenanthroline and $\mathrm{Fe}_{2} \mathrm{SO}_{4}$.

\subsection{ABTS radical scavenging activity}

The ABTS radical scavenging ability was determined as reported in the literature (Arts et al., 2004). A solution of the ABTS radical cation was prepared by mixing potassium persulfate $(2.45 \mathrm{mM})$ with ABTS stock solution $(7 \mathrm{mM})$ at a volume ratio of 1:1. The mixture was kept in the dark for $12 \mathrm{~h}$. The ABTS solution was diluted with ethanol until its absorbance measurement at 
$734 \mathrm{~nm}(0.70 \pm 0.02)$. The diluted extract $(1 \mathrm{~mL})$ was mixed with $3 \mathrm{~mL}$ of ABTS solution and then allowed to stand in the dark for $7 \mathrm{~min}$ at room temperature. The ABTS scavenging ability was calculated through the following Equation 4:

ABTS scavenging activity $(\%)=\frac{A_{2}-\left(A_{1}-A_{0}\right)}{A_{2}} \times 100$

where $A_{0}$ is the absorbance of the sample without ABTS; $A_{1}$ is the absorbance of the sample with ABTS; and $A_{2}$ is the absorbance of the blank solution containing ABTS.

\section{Results and discussion}

\subsection{Single factor analysis}

The PC content increased rapidly when the liquid-to-solid ratio ranged from 5:1 to $15: 1$. However, it slightly decreased as the ratio continued to increase (Figure 1a). This result may be attributed to the presence of excess solvent, which may have influenced the cavitation effect of UAE. Therefore, 15:1 was deemed as the optimal liquid-to-solid ratio for PC production.

The PC content increased with increasing ethanol concentration up to $60 \%$ (Figure $1 \mathrm{~b}$ ), but it decreased thereafter. In general, the polarity of an ethanol-water mixture increases continuously upon addition of more water. A large proportion of polar phenolic compounds may be extracted according to the "like-dissolves-like" principle (Tabaraki \& Nateghi, 2011). When the solvent concentration amount exceeded a certain value, the polarity of the solvent changed and the phenolic compound extraction rate decreased (Feng et al., 2015). Therefore, the optimal ethanol concentration was $60 \%$.

From 10 to $30 \mathrm{~min}$ of UAE, the PC content increased, reaching a maximum at $30 \mathrm{~min}$ (Figure 1c). With prolonged extraction time, however, the extraction yield remained constant, suggesting that the PC had been completely extracted. Earlier studies have reported durations longer than 30 min caused PC
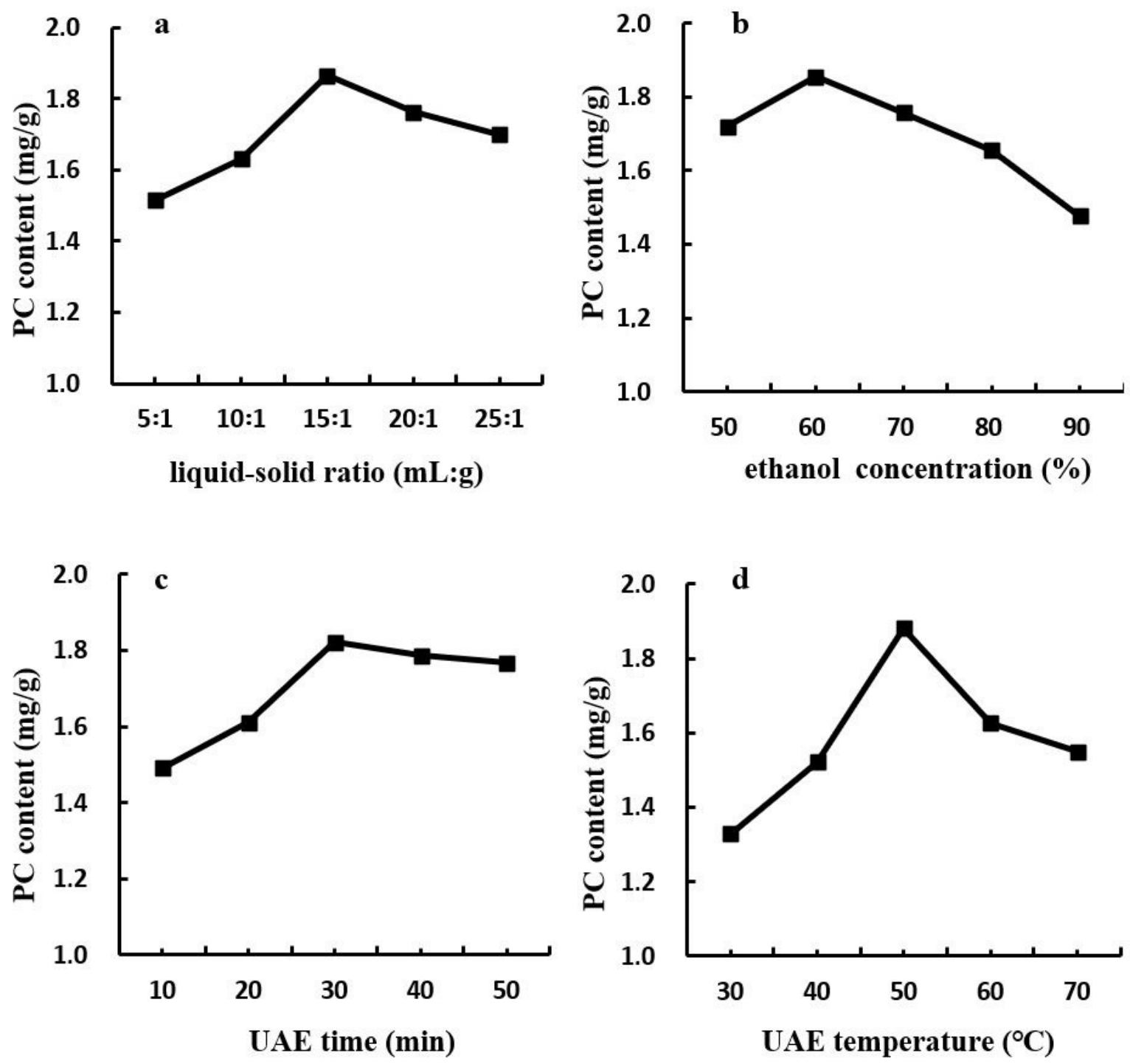

Figure 1. The effect of (a) liquid-to-solid ratio; (b) ethanol concentration; (c) UAE time; and (d) UAE temperature on the procyanidins content of perilla seed hull. UAE = Ultrasound-assisted extraction. 
degradation (Wissam et al., 2012). Therefore, the optimal UAE time was $30 \mathrm{~min}$.

As shown in Figure 1d, the PC content increased sharply when the UAE temperature increased from $30^{\circ} \mathrm{C}$ to $50^{\circ} \mathrm{C}$, declining gradually with further increase in UAE temperature. This result is consistent with findings obtained with proanthocyanidins from guava leaves (Díaz-de-Cerio et al., 2017). High temperature decreased the number of cavitation bubbles and weakened the impact of cavity collapse on the ground samples (Zhao et al., 2007; Zheng et al., 2014). Thus, the PC content decreased when the UAE temperature was over $50^{\circ} \mathrm{C}$, which was then deemed the optimal UAE temperature.

\subsection{Second-order polynomial model}

The experimental conditions and the PC content based on the RSM design are shown in Table 1; the ANOVA results are shown in Table 2. The model $F$ value of 14.03 and the low $P$ value $(<0.0001)$ reveal that the model is significant. Meanwhile, the determination coefficient $\left(R^{2}=0.9335\right)$ and the adjusted determination coefficient (adj. $R^{2}=0.8670$ ) also confirm that the model is adequate. According to Le Man et al. (2010), a model is adequate when $R^{2}>0.75$. Additionally, the lack of fit, which measures the fitness of the model, was not significant $(P>0.05)$. Adeq precision measures the signal-to-noise ratio; a ratio greater than 4 is desirable. Thus, the ratio of 13.68 indicates an adequate signal and the adequacy of the model for navigating the design

Table 2. Analysis of variance (ANOVA) for the quadratic polynomial mode.

\begin{tabular}{cccccc}
\hline Source & $\begin{array}{c}\text { Sum of } \\
\text { squares }\end{array}$ & df & $\begin{array}{c}\text { Mean } \\
\text { square }\end{array}$ & $F$-value & $P$-value \\
\hline Model & 1.582 & 14 & 0.113 & 14.03 & $<0.0001$ \\
$X_{1}$ & 0.004 & 1 & 0.004 & 0.496 & 0.4927 \\
$X_{2}$ & 0.125 & 1 & 0.125 & 15.58 & 0.0015 \\
$X_{3}$ & 0.103 & 1 & 0.103 & 12.80 & 0.0030 \\
$X_{4}$ & 0.089 & 1 & 0.089 & 11.02 & 0.0051 \\
$X_{1} X_{2}$ & 0.020 & 1 & 0.020 & 2.486 & 0.1372 \\
$X_{1} X_{3}$ & 0.038 & 1 & 0.038 & 4.770 & 0.0465 \\
$X_{1} X_{4}$ & 0.003 & 1 & 0.003 & 0.376 & 0.5498 \\
$X_{2} X_{3}$ & 0.048 & 1 & 0.048 & 5.983 & 0.0283 \\
$X_{2} X_{4}$ & 0.103 & 1 & 0.103 & 12.83 & 0.0030 \\
$X_{3} X_{4}$ & 0.050 & 1 & 0.050 & 6.258 & 0.0254 \\
$X_{1}^{2}$ & 0.137 & 1 & 0.137 & 17.03 & 0.0010 \\
$X_{2}^{2}$ & 0.578 & 1 & 0.577 & 71.61 & $<0.0001$ \\
$X_{3}^{2}$ & 0.508 & 1 & 0.508 & 63.06 & $<0.0001$ \\
$X_{4}^{2}$ & 0.249 & 1 & 0.249 & 30.88 & $<0.0001$ \\
Residual & 0.113 & 14 & 0.008 & & \\
Lack of fit & 0.102 & 10 & 0.010 & 3.708 & 0.1091 \\
Pure error & 0.011 & 4 & 0.003 & & \\
Cor total & 1.695 & 28 & & & \\
$R^{2}$ & 0.9335 & & & & \\
Adj. $R^{2}$ & 0.8670 & & & & \\
Adeq & 13.68 & & & & \\
precision & & & & & \\
${ }^{2} P<0.01$ highly & signifint; $0.01<P<0.05$ significant $P>0.05$ notsignificant
\end{tabular}

${ }^{\star} P<0.01$ highly significant; $0.01<P<0.05$ significant; $P>0.05$ not significant. space. The results reveal that the response variable and the independent variables are related by the following second-order polynomial Equation 5:

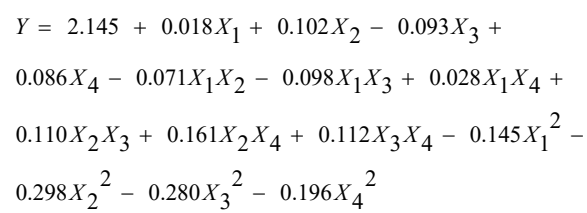

The $P$-value is used as a tool to check the significance of each coefficient. It could be observed that the effects of $X_{2}, X_{3}$, $X_{4}, X_{2} X_{4}, X_{1}^{2}, X_{2}^{2}, X_{3}^{2}$ and $X_{4}^{2}$ on the PC content were highly significant $(P<0.01)$. Similarly, the effects of $X_{1} X_{3}, X_{2} X_{3}$ and $X_{3} X_{4}$ were significant $(P<0.05)$. On the other hand, $X_{1}, X_{1} X_{2}$ and $X_{1} X_{4}$ had no significant effects $(P>0.05)$ on the PC content.

\subsection{RSM analysis}

The relationships between independent and dependent variables are illustrated by three-dimensional response surface graphs in Figure 2. From the response-surface plots, the PC content was obtained along with two continuous variables, while the other two variables were fixed constant at their respective zero levels. The shapes of the contour plots, elliptical or circular, indicate whether the interactions between the corresponding variables were significant (Jin et al., 2012).

The effects of liquid-to-solid ratio and ethanol concentration on the PC content at constant extraction time $(30 \mathrm{~min})$ and temperature $\left(50^{\circ} \mathrm{C}\right)$ are depicted in Figure 2a. The interaction effect between these two variables was not significant $(P>0.05)$. The PC content increased before the liquid-to-solid ratio increased to a threshold level of 15.29:1, but it decreased slightly. Similarly, the PC content increased with the ethanol concentration in the range of $50 \%$ to $62.32 \%$, and then decreased. This result is consistent with findings obtained with phenolic compounds from sugarcane rinds (Feng et al., 2015). We obtained the maximum PC content when the liquid-to-solid ratio and ethanol concentration were $15.29: 1$ and $62.32 \%$, respectively.

Figure $2 b$ shows the effect of the liquid-to-solid ratio and UAE time on the PC content at constant ethanol concentration $(60 \%)$ and UAE temperature $\left(50^{\circ} \mathrm{C}\right)$. As the UAE time increased from 20 to $29 \mathrm{~min}$, the PC content increased as well. Since the curve did not level off for a short period, this UAE time was well below the optimum for PC content. There was a linear increase in the PC content as the liquid-to-solid ratio increased from 10:1 to $15.29: 1$, subsequently declining slightly with increasing ratio. The effect of extraction time was more significant than that of the liquid-to-solid ratio because the system may have already reached equilibrium with extended extraction time (Li et al., 2015).

The effects of liquid-to-solid ratio and temperature on the PC content at constant ethanol concentration $(60 \%)$ and extraction time $(30 \mathrm{~min})$ are presented in Figure $2 \mathrm{c}$. The interaction between these two variables had a non-significant effect on the PC content; however, the quadratic variables had significant effects $(P<0.01)$. This result may be attributed to the effect of extraction time, which stabilizes the system at $15 \mathrm{~min}$. 
The effects of the ethanol concentration and UAE time on the PC content can be seen in Figure 2d. The linear and quadratic effects of ethanol concentration were significant $(P<0.01)$, indicating that increasing the ethanol concentration favors extraction of PC only up to a certain value (62.32\%). At higher ethanol concentrations, the PC content decreased. We also found
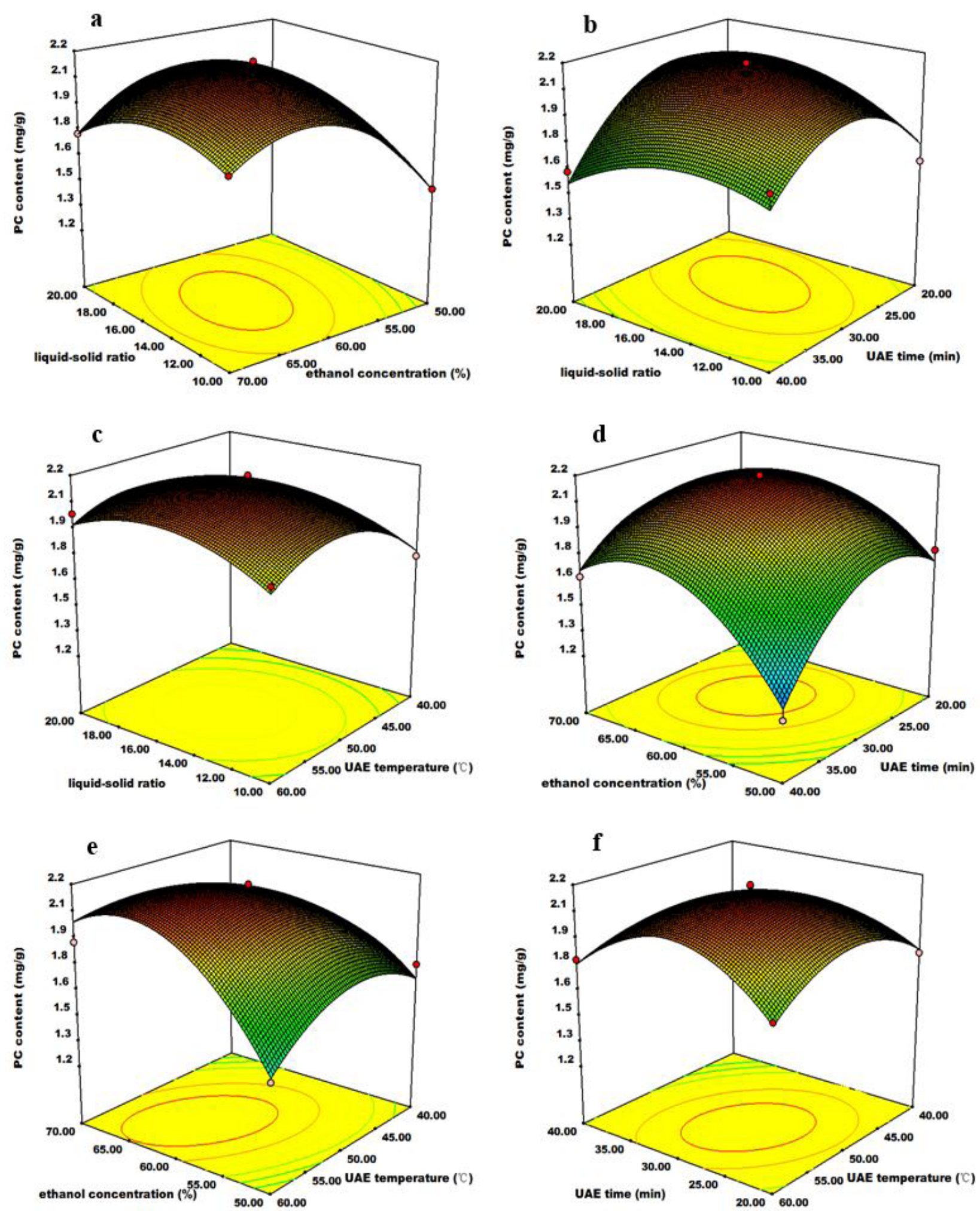

Figure 2. Response surface plots for the effect of (a) liquid-to-solid ratio and ethanol concentration; (b) liquid-to-solid ratio and UAE time; (c) liquid-to-solid ratio and UAE temperature; (d) ethanol concentration and UAE time; (e) ethanol concentration and UAE temperature; and (f) UAE time and UAE temperature on the procyanidins content. UAE = Ultrasound-assisted extraction. 
that the maximum PC content was achievable with the UAE time at the threshold level of $29 \mathrm{~min}$. However, when the UAE time exceeded the threshold level, the PC content decreased, indicating that a suitable ethanol concentration is important for PC extraction.

Figure 2e shows the effect of ethanol concentration and UAE temperature on the PC content at constant liquid-to-solid ratio (15:1) and UAE time (30 $\mathrm{min})$. The interaction between these two variables had highly significant effects on the PC content $(P<0.01)$. We can see that the lower was the ethanol concentration, the lower was the PC content. The PC content increased with the ethanol concentration in the range of 50 to $62 \%$, and then changed little. Similarly, the PC content slowly increased with the increase in temperature, reaching a maximal value at $52.99^{\circ} \mathrm{C}$. It is therefore likely that a suitable extraction temperature improves the target-compound solubility, solvent diffusion rate, and mass transfer (Hossain et al., 2011).

Figure $2 \mathrm{f}$ shows the effect of the UAE time and UAE temperature on the PC content at constant liquid-to-solid ratio (7:1) and ethanol concentration (60\%). The interaction between these two variables had significant effects on the PC content $(P<0.05)$. As shown in the response surface plot, the PC content increased and reached maximum levels at $52.99^{\circ} \mathrm{C}$ and $29.29 \mathrm{~min}$ and that a continued increase in time and temperature led to a decrease in PC content. Higher temperatures and longer times lowered the PC content probably because PC degraded, a phenomenon similar to that in a previous report (Wissam et al., 2012).

\subsection{Optimization of the conditions}

According to the second-order polynomial equation, the optimum conditions for PC content are as follows: a liquid-to-solid ratio of 15.29:1, an ethanol concentration of $62.32 \%$, a UAE time of $29.29 \mathrm{~min}$, and a UAE temperature of $52.99^{\circ} \mathrm{C}$. The predicted maximum PC content was $2.2 \mathrm{mg} / \mathrm{g}$. Considering the operability in actual production, we slightly modified the optimum conditions to the following: a liquid-to-solid ratio of 15:1, an ethanol concentration of $62 \%$, a UAE time of $29 \mathrm{~min}$, and a UAE temperature of $53^{\circ} \mathrm{C}$. Under these conditions, a mean PC content of $2.185 \mathrm{mg} / \mathrm{g}(\mathrm{n}=3)$ was obtained. The results imply that the experimental value is consistent with the predicted values. The extraction conditions obtained by RSM were not only accurate and reliable, but they also had practical value (Xu et al., 2013).

Several authors have reported some conditions for PC extraction. For example, the best extraction temperature achieved is in agreement with Liu et al. (2010); in contrast, they showed higher ethanol concentration (67.5\%) and longer extraction time (1.6 h) with traditional Soxhlet extraction method. Dailey \& Vuong (2015) found that the temperature and time have no significant effect on PC extraction of macadamia skin waste; this result is in contrast to our findings obtained with PC extraction of perilla seed hull and to those for extraction of jabuticaba peel by Rodrigues et al. (2015).

\subsection{DPPH radical scavenging activity}

DPPH is a useful reagent for investigating the free radical scavenging activities of natural compounds (Liu et al., 2015). Figure 3a illustrates the scavenging activities of the purified PC and
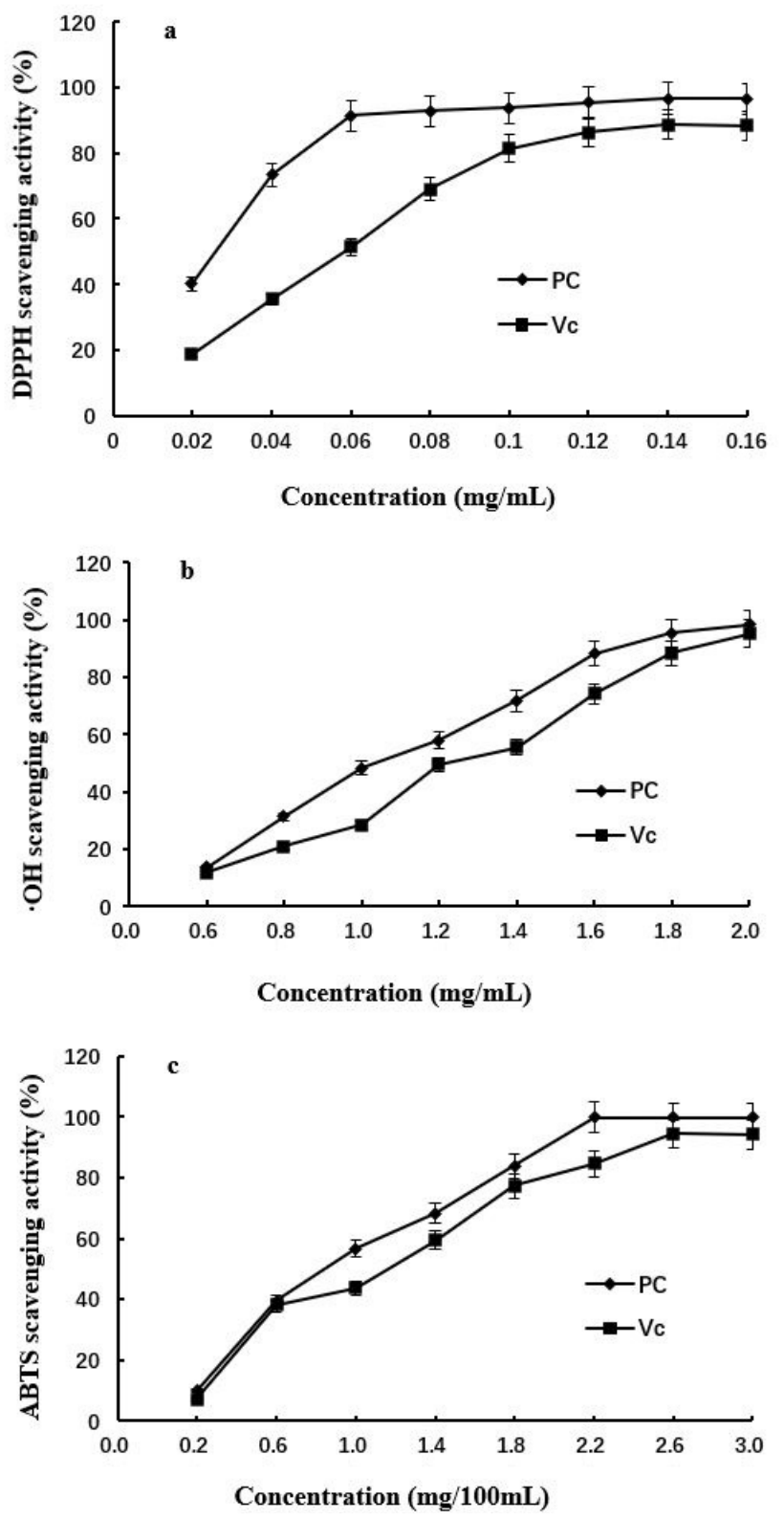

Figure 3. Scavenging effects of procyanidins on (a) DPPH; (b) hydroxyl; and (c) ABTS radicals. Data were shown as mean $(n=3)$. The vertical bars represented the standard deviation of each data point $(P<0.05)$.

Ascorbic Acid (Vc) against the DPPH radical. At concentrations of $0.02 \mathrm{mg} / \mathrm{mL}$ to $0.16 \mathrm{mg} / \mathrm{mL}$, the DPPH radical scavenging activity increased with the Vc concentration until a maximum of $88.55 \%$ at $0.14 \mathrm{mg} / \mathrm{mL}$, whereas the maximum scavenging rate of PC could reach $96.75 \%$ at $0.14 \mathrm{mg} / \mathrm{mL}$. The half-inhibition concentration $\left(I C_{50}\right)$ is defined as the concentration of the sample at which the scavenging rate reaches $50 \%$; a lower $I C_{50}$ corresponds to a stronger antioxidant activity of the tested sample (Zheng et al., 2014). The $I C_{50}$ vales for DPPH radical scavenging activities for $\mathrm{PC}$ and $\mathrm{Vc}$ were 0.02 and $0.05 \mathrm{mg} / \mathrm{mL}$, respectively, indicating that PC had a noticeable effect on scavenging DPPH radicals and that the scavenging ability of PC is higher than that of $\mathrm{Vc}$ at all of the investigated concentrations. 


\subsection{Hydroxyl radical scavenging activity}

The hydroxyl radical is the most reactive free radical among the oxygen radicals. It severely damages biomolecules such as proteins, DNA, polyunsaturated fatty acids, and almost any biological molecule it encounters (Liu et al., 2010). Therefore, removal of the hydroxyl radical is extremely important for the protection of living systems. Figure $3 \mathrm{~b}$ shows that the hydroxyl radical scavenging abilities of perilla $\mathrm{PC}$ and $\mathrm{Vc}$ were concentration-dependent. The maximum hydroxyl radical scavenging activities of $\mathrm{PC}$ and Vc were $98.38 \%$ and $95.25 \%$ at a concentration of $2 \mathrm{mg} / \mathrm{mL}$. The $I C_{50}$ values calculated from the regression equation were 1.04 and $1.27 \mathrm{mg} / \mathrm{mL}$ for $\mathrm{PC}$ and $\mathrm{Vc}$, respectively. These results indicate that perilla PC has ability for hydroxyl radical scavenging that is stronger than that of Vc.

\subsection{ABTS radical scavenging activity}

The ABTS radical scavenging activities of $\mathrm{PC}$ and $\mathrm{Vc}$ (Figure 3c) evidence the scavenging effects of PC and Vc under all the tested concentrations. Good correlations between ABTS radical scavenging activities and sample concentration were found $\left(y=12.77 x-0.565, R^{2}=0.908\right.$ for PC; $y=12.29 x-5.352$, $R^{2}=0.938$ for $\mathrm{Vc}$ ). The maximum scavenging activities of $\mathrm{PC}$ and $\mathrm{Vc}$ were $99.78 \%$ and $94.35 \%$ at concentrations of 2.2 and $2.6 \mathrm{mg} / 100 \mathrm{~mL}$, respectively. The ABTS radical scavenging activity of perilla PC was also higher than that of $\mathrm{Vc}$; the $I C_{50}$ values were 0.76 and $1.19 \mathrm{mg} / 100 \mathrm{~mL}$ for PC and $\mathrm{Vc}$, respectively.

\section{Conclusion}

In this study, an efficient UAE technique was employed to extract PC from the perilla seed hull. A BBD was employed to optimize the extraction parameters. The optimal conditions for PC extraction were as follows: a liquid-to-solid ratio of 15:1, an ethanol concentration of $62 \%$, a UAE time of $29 \mathrm{~min}$, and a UAE temperature of $53^{\circ} \mathrm{C}$. Under these conditions, the experimental yield of PC was $2.185 \mathrm{mg} / \mathrm{g}(\mathrm{n}=3)$, which is correlated with the predicted value of $2.2 \mathrm{mg} / \mathrm{g}$. The application of ultrasound-assisted extraction offers many advantages, including the reduction of solvents and of time for extraction (Tabaraki \& Nateghi, 2011; Hossain et al., 2012). Therefore, UAE is an effective and environment-friendly process ( $\mathrm{Li}$ et al., 2016) for the preparation of extracts from perilla seed hull. Moreover, procyanidins from perilla seed hull exhibited strong antioxidant effects in the DPPH, hydroxyl and ABTS assays in vitro. The results suggest that perilla PC may be developed as a potential natural antioxidant for the pharmaceutical and food industries.

\section{Acknowledgements}

This work was supported by the Science and Technology Research Program in Social Development of Shanxi Province (201603D321031) and Science and Technology Research Program in Agriculture of Shanxi Province (20150311009-4).

\section{References}

Aneta, W., Jan, O., Magdalena, M., \& Joanna, W. (2013). Phenolic profile, antioxidant and antiproliferative activity of black and red currants (Ribes spp.) from organic and conventional cultivation.
International Journal of Food Science \& Technology, 48(4), 715-726. http://dx.doi.org/10.1111/ijfs.12019.

Arts, M. J. T. J., Haenen, G. R. M. M., Voss, H. P., \& Bast, A. (2004). Antioxidant capacity of reaction products limits the applicability of the trolox equivalent antioxidant capacity (TEAC) assay. Food and Chemical Toxicology, 42(1), 45-49. http://dx.doi.org/10.1016/j. fct.2003.08.004. PMid:14630129.

Asif, M. (2011). Health effects of omega-3,6,9 fatty acids: Perilla frutescens is a good example of plant oils. Oriental Pharmacy and Experimental Medicine, 11(1), 51-59. http://dx.doi.org/10.1007/ s13596-011-0002-x. PMid:21909287.

Avellar, I. G., Magalhães, M. M., Silva, A. B., Souza, L. L., Leitao, A. C., \& Hermes-Lima, M. (2004). Reevaluating the role of 1,10-phenanthroline in oxidative reactions involvingferrous ions and DNA damage. Biochimica et Biophysica Acta, 1675(1-3), 46-53. http://dx.doi. org/10.1016/j.bbagen.2004.08.006. PMid:15535966.

Azmir, J., Zaidul, I. S. M., Rahman, M. M., Sharif, K. M., Sahena, F., Jahurul, M. H. A., \& Mohamed, A. (2014). Optimization of oil yield of Phaleria macrocarpa seed using response surface methodology and its fatty acids constituents. Industrial Crops and Products, 52, 405-412. http://dx.doi.org/10.1016/j.indcrop.2013.11.009.

Berendsen, R., Güell, C., \& Ferrando, M. (2015). A procyanidin-rich extract encapsulated in water-in-oil-in-water emulsions produced by premix membrane emulsification. Food Hydrocolloids, 43, 636648. http://dx.doi.org/10.1016/j.foodhyd.2014.07.023.

Box, G. E., \& Wilson, K. G. (1951). On the experimental attainment of optimum conditions. Journal of the Royal Statistical Society Series A, 13, 1-45.

Chen, M., Zhao, Y., \& Yu, S. J. (2015). Optimisation of ultrasonic-assisted extraction of phenolic compounds, antioxidants, and anthocyanins from sugar beet molasses. Food Chemistry, 172, 543-550. http:// dx.doi.org/10.1016/j.foodchem.2014.09.110. PMid:25442590.

Choi, H. S., Song, H. S., Ukeda, H., \& Sawamura, M. (2000). Radical scavenging activities of Citrus essential oils and their components: detection using 1,1-diphenyl-2-picrylhydrazyl. Journal of Agricultural and Food Chemistry, 48(9), 4156-4161. http://dx.doi.org/10.1021/ jf000227d. PMid:10995330.

Ciftci, O. N., Przybylski, R., \& Rudzińska, M. (2012). Lipid components of flax, perilla, and chia seeds. European Journal of Lipid Science and Technology, 114(7), 794-800. http://dx.doi.org/10.1002/ejlt.201100207.

Cruz, L., Fernandes, V. C., Araújo, P., Mateus, N., \& Freitas, V. (2015). Synthesis, characterization and antioxidant features of procyanidin B4 and malvidin-3-glucoside stearic acid derivatives. Food Chemistry, 174, 480-486. http://dx.doi.org/10.1016/j.foodchem.2014.11.062. PMid:25529709.

Dailey, A., \& Vuong, Q. V. (2015). Optimization of ultrasonic conditions as an advanced extraction technique for recovery of phenolic compounds and antioxidant properties from macadamia (Macadamia tetraphylla) skin waste. Technologies, 3(4), 302-320. http://dx.doi. org/10.3390/technologies3040302.

Díaz-de-Cerio, E., Pasini, F., Verardo, V., Fernández-Gutiérrez, A., Segura-Carretero, A., \& Caboni, M. F., \& Psidiumguajava, L. (2017). leaves as source of proanthocyanidins: Optimization of the extraction method by RSM and study of the degree of polymerization by NPHPLC-FLD-ESI-MS. Journal of Pharmaceutical and Biomedical Analysis, 133, 1-7. http://dx.doi.org/10.1016/j.jpba.2016.10.011. PMid:27780121.

Feng, S., Luo, Z., Tao, B., \& Chen, C. (2015). Ultrasonic-assisted extraction and purification of phenolic compounds from sugarcane (Saccharum officinarum L.) rinds. Lebensmittel-Wissenschaft + Technologie, 60(2), 970-976. http://dx.doi.org/10.1016/j.lwt.2014.09.066. 
Ha, T. J., Lee, J. H., Lee, M. H., Lee, B. W., Kwon, H. S., Park, C. H., Shim, K. B., Kim, H. T., Baek, I. Y., \& Jang, D. S. (2012). Isolation and identification of phenolic compounds from the seeds of perilla frutescens (L.) and their inhibitory activities against alpha-glucosidase and aldose reductase. Food Chemistry, 135(3), 1397-1403. http:// dx.doi.org/10.1016/j.foodchem.2012.05.104. PMid:22953872.

Hammerstone, J. F., Lazarus, S., \& Schmitz, H. (2000). Procyanidin content and variation in some commonly consumed foods. The Journal of Nutrition, 130(8S, Suppl), 2086S-2092S. http://dx.doi. org/10.1093/jn/130.8.2086S. PMid:10917927.

Hossain, M. B., Barry-Ryan, C., Martin-Diana, A. B., \& Brunton, N. P. (2011). Optimisation of accelerated solvent extraction of antioxidant compounds from rosemary (Rosmarinus officinalis L.), marjoram (Origanum majorana L.) and oregano (Origanum vulgare L.) using response surface methodology. Food Chemistry, 126(1), 339-346. http://dx.doi.org/10.1016/j.foodchem.2010.10.076.

Hossain, M. B., Brunton, N. P., Patras, A., Tiwari, B., O’Donnell, C. P., Martin-Diana, A. B., \& Barry-Ryan, C. (2012). Optimization of ultrasound assisted extraction of antioxidant compounds from marjoram (Origanum majorana L.) using response surface methodology. Ultrasonics Sonochemistry, 19(3), 582-590. http:// dx.doi.org/10.1016/j.ultsonch.2011.11.001. PMid:22172467.

Igarashi, M., \& Miyazaki, Y. (2013). A review on bioactivities of perilla: progress in research on the functions of perilla as medicine and food. Evidence-Based Complementary and Alternative Medicine, 2013, 1-7. http://dx.doi.org/10.1155/2013/925342. PMid:24319488.

Jin, L., Guan, X., Liu, W., Zhang, X., Yan, W., Yao, W. B., \& Gao, X. D. (2012). Characterization and antioxidant activity of a polysaccharide extracted from Sarcandra glabra. Carbohydrate Polymers, 90(1), 524532. http://dx.doi.org/10.1016/j.carbpol.2012.05.074. PMid:24751073.

Le Man, H., Behera, S. K., \& Park, H. S. (2010). Optimization of operational parameters for ethanol production from Korean food waste leachate. International Journal of Environmental Science and Technology, 7(1), 157-164. http://dx.doi.org/10.1007/BF03326127.

Li, H. Z., Zhang, Z. J., Hou, T. Y., Li, X. J., \& Chen, T. (2015). Optimization of ultrasound-assisted hexane extraction of perilla oil using response surface methodology. Industrial Crops and Products, 76, 18-24. http://dx.doi.org/10.1016/j.indcrop.2015.06.021.

Li, H. Z., Zhang, Z. J., Xue, J., Cui, L. X., Hou, T. Y., Li, X. J., \& Chen, T. (2016). Optimization of ultrasound-assisted extraction of phenolic compounds, antioxidants and rosmarinic acid from perilla leaves using response surface methodology. Food Science and Technology, 36(4), 686-693. http://dx.doi.org/10.1590/1678-457x.13516.

Li, Y., Zhang, Y., Sui, X. N., Zhang, Y. N., Feng, H. X., \& Jiang, L. Z. (2014). Ultrasound-assisted aqueous enzymatic extraction of oil from perilla (Perilla frutescens L.) seeds. CYTA: Journal of Food, 12(1), 16-21. http://dx.doi.org/10.1080/19476337.2013.782070.

Liu, J. L., Zheng, S. L., Fan, Q. J., Yuan, J. C., Yang, S. M., \& Kong, F. L. (2015). Optimisation of high-pressure ultrasonic-assisted extraction and antioxidant capacity of polysaccharides from the rhizome of Ligusticum chuanxiong. International Journal of Biological Macromolecules, 76, 80-85. http://dx.doi.org/10.1016/j. ijbiomac.2015.02.031. PMid:25732619.

Liu, J., Wan, Y., Zhao, Z. Z., \& Chen, H. B. (2013). Determination of the content of rosmarinic acid by HPLC and analytical comparison of volatile constituents by GC-MS in different parts of Perilla frutescens (L.) Britt. Chemistry Central Journal, 7(1), 61-71. http://dx.doi. org/10.1186/1752-153X-7-61. PMid:23548079.

Liu, T. X., Cao, Y. N., \& Zhao, M. M. (2010). Extraction optimization, purification and antioxidant activity of procyanidins from hawthorn
(C. pinnatifida Bge. Var. major) fruits. Food Chemistry, 119(4), 16561662. http://dx.doi.org/10.1016/j.foodchem.2009.09.001.

Longvah, T., \& Deosthale, Y. G. (1998). Effect of dehulling, cooking and roasting on the protein quality of Perilla frutescens seed. Food Chemistry, 63(4), 519-523. http://dx.doi.org/10.1016/S03088146(98)00030-2.

Moure, A., Cruz, J. M., Franco, D., Domínguez, J. M., Sineiro, J., Domínguez, H., José Núñez, M., \& Parajó, J. C. (2001). Natural antioxidants from residual sources. Food Chemistry, 72(2), 145-171. http://dx.doi.org/10.1016/S0308-8146(00)00223-5.

Rodrigues, S., Fernandes, F. A. N., de Brito, E. S., Sousa, A. D., \& Narain, N. (2015). Ultrasound extraction of phenolics and anthocyanins from jabuticaba peel. Industrial Crops and Products, 69, 400-407. http://dx.doi.org/10.1016/j.indcrop.2015.02.059.

Santos-Buelga, C., \& Scalbert, A. (2000). Proanthocyanidins and tannin-like compounds: nature, occurrence, dietary intake and effects on nutrition and health. Journal of the Science of Food and Agriculture, 80(7), 1094-1117. http://dx.doi.org/10.1002/(SICI)10970010(20000515)80:7<1094::AID-JSFA569>3.0.CO;2-1.

Seong, J., \& Song, Y. O. (2012). Perilla oil rich in $\alpha$-linolenic acid inhibits neuronal apoptosis and the expression of inflammation-mediator protein in apoE KO mice. Biocatalysis and Agricultural Biotechnology, 1(2), 167-173. http://dx.doi.org/10.1016/j.bcab.2012.01.001.

Sharma, B. D., Hore, D. K., \& Mondal, S. (1989). Perilla: an oil and protein rich underexploited crop of Northeast Hill. Journal of Oilseeds Research, 6, 386-389.

Shin, H. S., \& Kim, S. W. (1994). Lipid composition of perilla seed. Journal of the American Oil Chemists' Society, 71(6), 619-622. http:// dx.doi.org/10.1007/BF02540589.

Su, X., Howell, A. B., \& D’Souza, D. H. (2010). Antiviral effects of cranberry juice and cranberry proanthocyanidins on foodborne viral surrogates: a time dependence study in vitro. Food Microbiology, 27(8), 985-991. http://dx.doi.org/10.1016/j.fm.2010.05.027. PMid:20832675.

Tabaraki, R., \& Nateghi, A. (2011). Optimization of ultrasonic-assisted extraction of natural antioxidants from rice bran using response surface methodology. Ultrasonics Sonochemistry, 18(6), 1279-1286. http://dx.doi.org/10.1016/j.ultsonch.2011.05.004. PMid:21612968.

Wissam, Z., Ghada, B., Wassim, A., \& Warid, K. (2012). Effective extraction of polyphenols and proanthocyanidins from pomegranates peel. International Journal of Pharmacy and Pharmaceutical Sciences, $4,675-682$.

Xu, Q., Shen, Y. Y., Wang, H. F., Zhang, N. P., Xu, S. H., \& Zhang, L. (2013). Application of response surface methodology to optimize extraction of flavonoids from fructus sophorae. Food Chemistry, 138(4), 2122-2129. http://dx.doi.org/10.1016/j.foodchem.2012.11.099. PMid:23497866.

Yang, L., Sun, X. W., Yang, F. J., Zhao, C. J., Zhang, L., \& Zu, Y. G. (2012). Application of ionic liquids in the microwave-assisted extraction of proanthocyanidins from Larix gmelini bark. International Journal of Molecular Sciences, 13(4), 5163-5178. http://dx.doi.org/10.3390/ ijms13045163. PMid:22606036.

Zeković, Z., Vidović, S., Vladić, J., Radosavljević, R., Cvejin, A., Elgndi, M. A., \& Pavlić, B. (2014). Optimization of subcritical water extraction of antioxidants from Coriandrum sativum seeds by response surface methodology. The Journal of Supercritical Fluids, 95, 560-566. http:// dx.doi.org/10.1016/j.supflu.2014.09.004.

Zhang, L. H., Fu, Q. J., \& Zhang, Y. H. (2011). Composition of anthocyanins in pomegranate flowers and their antioxidant activity. Food Chemistry, 127(4), 1444-1449. http://dx.doi.org/10.1016/j. foodchem.2011.01.077. 
Zhao, S. N., Kwok, K. C., \& Liang, H. H. (2007). Investigation on ultrasound assisted extraction of saikosaponins from Radix Bupleuri. Separation and Purification Technology, 55(3), 307-312. http://dx.doi. org/10.1016/j.seppur.2006.12.002.

Zheng, Y., Li, Y., \& Wang, W. D. (2014). Optimization of ultrasonicassisted extraction and in vitro antioxidant activities of polysaccharides from Trametes orientalis. Carbohydrate Polymers, 111, 315-323. http://dx.doi.org/10.1016/j.carbpol.2014.04.034. PMid:25037357.

Zhou, X. J., Yan, L. L., Yin, P. P., Shi, L. L., Zhang, J. H., Liu, Y. J., \& Ma, C. (2014). Structural characterisation and antioxidant activity evaluation of phenolic compounds from cold-pressed Perilla frutescens var. arguta seed flour. Food Chemistry, 164, 150-157. http://dx.doi. org/10.1016/j.foodchem.2014.05.062. PMid:24996318. 